\title{
Formulation and Evaluation of Fixed Dose Combination Suppositories Containing Stavudine, Lamivudine and Nevirapine for Pediatric Applications
}

\author{
Y. Padmavathi*, B. M. Reddy, M. Renuka, K. Sumedha, N. P. Reddy \\ Department of Pharmaceutical Analysis and Quality Assurance, G. Pulla Reddy College of \\ Pharmacy, Osmania University, Hyderabad.500028, Telangana State, India
}

Received 13 September 2014, accepted in final revised form 24 June 2015

\begin{abstract}
Suppositories are the convenient way of administering drugs in infants. In view of the lack of suitable pediatric antiretroviral formulations in the market, suppositories containing fixed dose combination (FDC) of stavudine, lamivudine and nevirapine (SLN) were developed to allow administration of the correct weight-related dose in pediatric HIV patients as recommended by WHO. Suppositories containing $10 \mathrm{mg}$ of stavudine, $40 \mathrm{mg}$ of lamivudine and $70 \mathrm{mg}$ of nevirapine were prepared by the fusion method using Witepsol H15 semisynthetic suppository base. All the prepared suppositories were evaluated for various physical parameters like weight variation, melting point, drug content and hardness. The rate and extent of drug release was evaluated using USP apparatus I and samples were analyzed by a validated UV-multicomponent method. The use of surfactants significantly increased the drug release from formulations manufactured with Witepsol $\mathrm{H} 15$ fatty base. The development of pediatric fixed-dose combination formulations represent a new era and mark an important milestone for children living with HIV/AIDS.
\end{abstract}

Keywords: Witepsol H15; Suppositories; UV-multicomponent method; HIV/AIDS.

(c) 2015 JSR Publications. ISSN: 2070-0237 (Print); 2070-0245 (Online). All rights reserved. doi: http://dx.doi.org/10.3329/jsr.v7i3.20858 J. Sci. Res. 7 (3), 87-96 (2015)

\section{Introduction}

Combination therapy has now become the standard line of treatment to manage acquired immunodeficiency syndrome (AIDS) [1]. The need for such a therapy has arisen due to development of resistance by the causative human immunodeficiency virus (HIV), to single anti-HIV drugs and to minimize potential dose-dependent side effects [2]. The US Department of Health and Human Services has recommended highly effective combination regimens of antiretroviral drugs to combat mortality and morbidity in

\footnotetext{
* Corresponding author: ypadmavathi@gprcp.ac.in
} 
humans [3]. The current regimen for treating HIV infection is to use a combination of at least three drugs, generally includes two nucleoside reverse transcriptase inhibitors (NRTI) and a non nucleoside reverse transcriptase (NNRTI) or protease inhibitor.

Nucleoside reverse transcriptase inhibitors are triphosphorylated derivatives, which compete with the corresponding natural nucleotide for binding to HIV reverse transcriptase and non-nucleoside reverse transcriptase inhibitors act as non-competitive inhibitors of the HIV reverse transcriptase. Protease inhibitors a class of anti-HIV drugs which block the activity of the protease enzyme and helps in preventing maturation of the HIV virus. In combination therapy the synergistic action of different classes of anti-HIV drugs therapy has increased survival rate for AIDS patients [4]. Lamivudine (3TC), a nucleoside reverse transcriptase inhibitor is a synthetic dideoxynucleoside derivative with potent activity against human immunodeficiency virus (HIV) and hepatitis B virus (HBV) [5]. Its presence in antiretroviral regimens is important as it lowers toxicity than other nucleoside derivatives. It is administered orally and is rapidly absorbed with a bioavailability of more than $80 \%$ in humans. Stavudine is an analog of thymidine which is phosphorylated by cellular kinases into active triphosphate, inhibits the HIV reverse transcriptase by competing with natural substrate, thymidine triphosphate. The oral absorption rate is over $80 \%$. It's recommended in lower doses because of its adverse effect, peripheral neuropathy [6]. Nevirapine is a highly potent protease inhibitor. It displays activity in the immune system, including macrophages and $\mathrm{T}$ cells. It has very good oral absorption and its half-life is $45 \mathrm{~h}$ approximately. NVP in triple combination therapy has been shown to suppress viral load effectively when used as initial antiretroviral therapy.<smiles>Nc1ccn(C2CSC(CO)O2)c(=O)n1</smiles><smiles>Cc1cn([C@H]2C=C[C@@H](CO)O2)c(=O)[nH]c1=O</smiles><smiles>Cc1cccc2c1NC(=O)c1cccnc1N2C1CC1</smiles>

Fig. 1. Chemical structures of lamivudine, stavudine and nevirapine.

Treatment of infants less than 6 months old with liquid formulations may be still a major problem. Data from the study of children treated with HIV antiretroviral (Children with HIV early antiretroviral) therapy showed a significant reduction (76\%) in mortality among infants who received antiretroviral therapy within 3 months of their life as opposed to those who were deferred therapy [7]. It is therefore beneficial to treat the infants rather deferring them to attain certain age, with conveniently and accurately administrable dosage forms. Suppository formulation is ideal solution to treat this patient population. Suppositories are the best choice of formulations, in cases where patients are 
uncooperative, unconscious or lack lucidity or when access to the intravenous route is compromised, children or patients in intensive care units. Rectal dosing may also be of value in achieving appropriate therapeutic outcomes for patients needing multiple drug therapy or continuous intravenous fluid infusion, where treatment is difficult or when there are few undamaged veins available for catheterization [8].

The aim of present study is to prepare suppositories containing the fixed dose combination (FDC) of stavudine, lamivudine and nevirapine (SLN) for pediatric use. There were no suppository formulations for fixed dose combination of HIV drugs [9-17]. The suppository formulations in these studies were prepared from semi synthetic fatty bases. As stavudine and lamivudine are hydrophilic drugs and nevirapine is a lipophilic drug, water soluble bases are not suitable for formulation design. Fatty bases like cocoa butter (Natural fatty base) and synthetic fatty base like Witepsol H15 can be used. Additional excipients used in the formulation studies are polysorbate 20, polysorbate 60 , polysorbate 80, propylene glycol and colloidal silicon dioxide.

\section{Experimental}

\subsection{Materials}

The following materials were obtained from commercial sources: stavudine, lamivudine and nevirapine (Dr. Reddys Laboratories, Hyderabad, Andhra Pradesh, India), Witepsol H 15 (Xenex laboratories, Canada), polysorbate 20, polysorbate 60, polysorbate 80, propylene glycol and colloidal silicon dioxide (S.D fine chemicals, Mumbai, India). All other reagents were analytical of reagent grade.

\subsection{Equipment}

Equipments used included USP dissolution apparatus (Electrolab, Mumbai, India), USP disintegration tester (Electrolab, Mumbai, India), and scanning UV-VIS spectrophotometer (Chemito, India).

\subsection{Preparation of suppositories}

Witepsol H15 (synthetic fatty base) was used as base for preparation of SLN suppositories. These were prepared by the fusion method by using metal molds [18]. The displacement value of witepsol H15 base was determined and the amount of SLN mixture required for each suppository formulation was calculated [19].

Each suppository was manufactured so as to contain an equivalent amount of $10 \mathrm{mg}$ stavudine, $40 \mathrm{mg}$ lamivudine and $70 \mathrm{mg}$ nevirapine in each one-gram suppository. Different formulations were prepared with and without the additives. The composition of different formulations prepared is given in the Table 1 . 


\subsection{Analysis of formulated suppositories [20]}

\subsubsection{Physical appearance}

The physical appearance of the formulated suppositories was performed visually. The color, shape and surface texture of the prepared formulation were evaluated visually and the size was measured by using vernier caliper and the observations were noted.

Table 1. Formulations of FDC SLN suppositories in Witepsol H15.

\begin{tabular}{|c|c|c|c|c|c|c|c|c|c|}
\hline \multirow{2}{*}{ Ingredients } & \multicolumn{9}{|c|}{ Formulation code } \\
\hline & W01 & W12 & W13 & W14 & W25 & W26 & W37 & W48 & W59 \\
\hline Stavudine (mg) & 10 & 10 & 10 & 10 & 10 & 10 & 10 & 10 & 10 \\
\hline Lamivudine (mg) & 40 & 40 & 40 & 40 & 40 & 40 & 40 & 40 & 40 \\
\hline Nevirapine (mg) & 70 & 70 & 70 & 70 & 70 & 70 & 70 & 70 & 70 \\
\hline Witepsol (g) & 0.920 & 0.920 & 0.920 & 0.920 & 0.920 & 0.920 & 0.920 & 0.920 & 0.920 \\
\hline Polysorbate 80 & - & 0.5 & - & - & 0.25 & 0.1 & & - & 0.5 \\
\hline Polysorbate 60 & & & 0.5 & & & & & & \\
\hline Polysorbate 20 & & & & 0.5 & & & & & \\
\hline Propylene glycol (\%) & - & - & - & - & & & 10 & - & \\
\hline Silicon dioxide (\%) & - & - & - & - & - & - & & 0.5 & 0.5 \\
\hline
\end{tabular}

\subsubsection{Weight variation}

From each formulation series, 20 randomly selected suppository samples were weighed individually, and the average weight and the percentage deviation values were calculated. Not more than two, if the individual weight deviates from the average weight by more than $5 \%$ and none by more than $10 \%$. The results are shown in Table 2 .

Table 2. Analysis of formulated suppositories.

\begin{tabular}{cccc}
\hline Formulation Code & Weight Variation \pm SD & Disintegration time $(\mathrm{min})$ & Melting range $\left({ }^{\circ} \mathrm{C}\right)$ \\
\hline W01 & $1.008 \pm 0.04$ & $15.75 \pm 0.50$ & $33.5-35.0$ \\
W12 & $0.997 \pm 0.04$ & $14.50 \pm 0.55$ & $32.5-36.5$ \\
W13 & $0.998 \pm 0.03$ & $14.19 \pm 0.85$ & $32.5-35.0$ \\
W14 & $1.101 \pm 0.01$ & $13.25 \pm 0.75$ & $32.5-36.0$ \\
W25 & $1.004 \pm 0.02$ & $13.50 \pm 0.40$ & $32.5-35.0$ \\
W26 & $1.020 \pm 0.01$ & $14.25 \pm 0.90$ & $32.5-36.5$ \\
W37 & $0.996 \pm 0.01$ & $13.00 \pm 0.50$ & $33.0-35.5$ \\
W48 & $1.150 \pm 0.02$ & $14.00 \pm 0.30$ & $33.0-35.5$ \\
W59 & $1.002 \pm 0.01$ & $14.19 \pm 0.98$ & $32.5-36.0$ \\
\hline
\end{tabular}

\subsubsection{Melting range}

A narrow melting point range is important for maintaining the shape of the suppository at the ambient storage conditions and for controlling the melting time after insertion into the rectum [21]. Each suppository sample was placed in a dialysis tube (15 cm long) and both ends of the tube were tied with a cotton thread. A thermometer was placed in each tube in contact with the mass of the sample and placed in a water bath maintained at $38^{\circ} \mathrm{C}$. The time required for each sample to melt completely with respect to the temperature was 
determined. Each melting point determination was performed in triplicate and the results of these tests are summarized and shown in Table 2.

\subsubsection{Disintegration}

The USP tablet disintegration apparatus was used to determine the disintegration of the prepared suppositories using $100 \mathrm{~mL}$ of water as the immersion fluid. A suppository was placed in each of the three tubes of the basket and was covered with a disk. The time required for each suppository to completely disintegrate at $37 \pm 5^{\circ} \mathrm{C}$ was determined.

\subsubsection{Content uniformity}

Drug content in the FDC SLN suppositories was determined by using UV spectrophotometric method. Suppository containing $10 \mathrm{mg}$ stavudine, $40 \mathrm{mg}$ lamivudine and $70 \mathrm{mg}$ nevirapine was made to dissolve in $100 \mathrm{~mL}$ of $\mathrm{pH} 7.4$ phosphate buffer solution at $37^{\circ} \mathrm{C}$. This solution was diluted appropriately and absorbance of the three drugs was measured at wavelength 265, 270 and $212 \mathrm{~nm}$ in multicomponent analysis mode using scanning UV-visible spectrophotometer. The results are given in Table 3.

\subsubsection{In-vitro drug release studies [22,23]}

The in vitro release of stavudine, lamivudine and nevirapine from the different suppository formulations prepared was assessed by carrying dissolution rate studies. The release studies were conducted at $37^{\circ} \mathrm{C} \pm 0.5^{\circ} \mathrm{C}$ using USP Apparatus I (basket type), with USP baskets of mesh size 40 filled in with glass beads in replicates of six, rotated at 75 rpm. The baskets were filled with three rows of glass beads and suppository is kept in the middle of the beads. Phosphate buffer (900 mL, $0.1 \mathrm{M}, \mathrm{pH} 7.4$ ) was used as the dissolution medium. The dissolution medium was degassed and filtered through a $0.45 \mu \mathrm{m}$ membrane using millipore vacuum pump. Samples $(5 \mathrm{~mL})$ were withdrawn the predetermined times. An equivalent volume $(5 \mathrm{~mL})$ of previously warmed phosphate buffer was immediately replaced from the dissolution vessels to compensate for the volume of the sample removed for analysis. Samples were analyzed using the UV spectrophotometric method in multicomponent analysis mode.

The dissolution profile and drug release studies of SV, LV and nevirapine from optimized Witepsol suppositories are illustrated in Fig. 2 and Table 5. The optimized formulation was analyzed and results are given in table 4 .

\subsubsection{Stability studies of fatty base formulations [24-26]}

Dosage forms and active ingredients must be stable chemically and physically for extended periods, to provide an adequate shelf-life for products. As per USP description of stability for suppositories in long term storage includes observations for evidence of oil 
stains on packaging materials and excessive softening, which is the major indication of instability in suppository products.

Table 3. Drug content of SLN suppositories.

\begin{tabular}{cccc}
\hline & \multicolumn{3}{c}{ Drug content $^{\mathrm{a}}(\%)$} \\
\cline { 2 - 4 } Formulation code & Stavudine & Lamivudine & Nevirapine \\
\hline W01 & $98.51 \pm 0.170$ & $98.91 \pm 0.495$ & $98.51 \pm 0.51$ \\
W12 & $99.03 \pm 0.92$ & $99.3 \pm 1206$ & $98.20 \pm 1.15$ \\
W13 & $98.55 \pm 1.02$ & $98.75 \pm 1.05$ & $98.35 \pm 1.54$ \\
W14 & $98.49 \pm 1.4$ & $101.84 \pm 0.79$ & $98.99 \pm 0.470$ \\
W25 & $100.07 \pm 0.980$ & $101.06 \pm 1.44$ & $98.56 \pm 0.901$ \\
W26 & $98.55 \pm 1.20$ & $98.75 \pm 1.35$ & $98.89 \pm 0.603$ \\
W37 & $99.3 \pm 1.06$ & $102.61 \pm 1.4$ & $98.99 \pm 1.09$ \\
W48 & $99.26 \pm 1.12$ & $99.62 \pm 0.621$ & $99.01 \pm 1.15$ \\
W59 & $100.19 \pm 1.55$ & $98.75 \pm 1.25$ & $98.50 \pm 1.26$ \\
\hline
\end{tabular}

$\mathrm{a}=$ mean \pm s.d, $\mathrm{n}=6$

Table 4. Analysis of optimized SLN suppository.

\begin{tabular}{|c|c|c|c|}
\hline W59 & Batch I & Batch II & Batch III \\
\hline 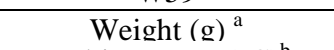 & $1.01 \pm 1.08$ & $1.02 \pm 1.20$ & $1.02 \pm 1.45$ \\
\hline Melting range $\left({ }^{\circ} \mathrm{C}\right)^{\mathrm{b}}$ & $32.5-36.0$ & $33.0-36.5$ & $33-36$ \\
\hline Disintegration time (min) & $14.11 \pm 1.11$ & $14.31 \pm 1.41$ & $14.01 \pm 0.981$ \\
\hline \multicolumn{4}{|c|}{ Drug content $(\%)^{\mathrm{c}}$} \\
\hline Stavudine & 99.30 & 99.50 & 99.10 \\
\hline Lamivudine & 99.62 & 99.39 & 99.51 \\
\hline Nevirapine & 99.01 & 99.23 & 99.60 \\
\hline
\end{tabular}

$\mathrm{a}=$ mean \pm s.d, $n=6 ; \mathrm{b}=$ mean \pm s.d, $n=3 ; \mathrm{c}=$ mean $\mathrm{n}=3$

USP recommends storage in a refrigerator. Rectal delivery systems must be stable under refrigerated $\left(4^{\circ} \mathrm{C} \pm 1^{\circ} \mathrm{C}\right)$ and ambient $\left(25^{\circ} \mathrm{C} \pm 3^{\circ} \mathrm{C}\right)$ storage conditions for at least two years. In order to determine whether or not FDC SLN suppositories prepared in our laboratories were potentially stable, preliminary stability studies were conducted for a period of one month at $4^{\circ} \mathrm{C}$ and room temperature, which was $22-25^{\circ} \mathrm{C}$. Six samples of best suppository formulation sealed in aluminum foil were kept at different environmental conditions as given below for about 4 weeks. The suppositories were evaluated every week for the following changes - color, shape, size, surface texture, disintegration time and drug release.

Table 5. Dissolution studies of optimized suppository.

\begin{tabular}{ccccccc}
\hline & \multicolumn{2}{c}{ Concentration of drug $(\mu \mathrm{g} / \mathrm{mL})$} & \multicolumn{3}{c}{ \% Drug released } \\
\cline { 2 - 7 } Time $(\mathrm{min})$ & $\mathrm{S}$ & $\mathrm{L}$ & $\mathrm{N}$ & $\mathrm{S}$ & $\mathrm{L}$ & $\mathrm{N}$ \\
\hline 30 & 1.26 & 4.911 & 6.897 & $11.93 \pm 0.231$ & $11.63 \pm 0.168$ & $9.33 \pm 0.122$ \\
60 & 3.093 & 7.412 & 10.025 & $29.30 \pm 0.141$ & $17.55 \pm 0.289$ & $13.56 \pm 0.467$ \\
90 & 3.39 & 11.768 & 18.34 & $32.11 \pm 0.531$ & $27.87 \pm 0.112$ & $24.82 \pm 0.211$ \\
120 & 6.426 & 13.528 & 23.731 & $60.87 \pm 0.131$ & $32.04 \pm 0.720$ & $32.11 \pm 0.982$ \\
180 & 7.965 & 21.943 & 40.105 & $75.45 \pm 0.630$ & $51.97 \pm 0.130$ & $54.27 \pm 0.420$ \\
240 & 9.871 & 30.123 & 55.211 & $93.51 \pm 0.713$ & $71.34 \pm 0.560$ & $74.72 \pm 0.560$ \\
\hline
\end{tabular}




\begin{tabular}{ccccccc}
\hline Time (min) & $\mathrm{S}$ & $\mathrm{L}$ & $\mathrm{N}$ & $\mathrm{S}$ & $\mathrm{L}$ & $\mathrm{N}$ \\
360 & 9.98 & 40.342 & 70.765 & $94.54 \pm 0.967$ & $95.54 \pm 0.312$ & $95.77 \pm 0.114$ \\
480 & 9.901 & 40.56 & 71.453 & $93.79 \pm 0.120$ & $96.06 \pm 0.456$ & $96.70 \pm 0.820$ \\
\hline
\end{tabular}

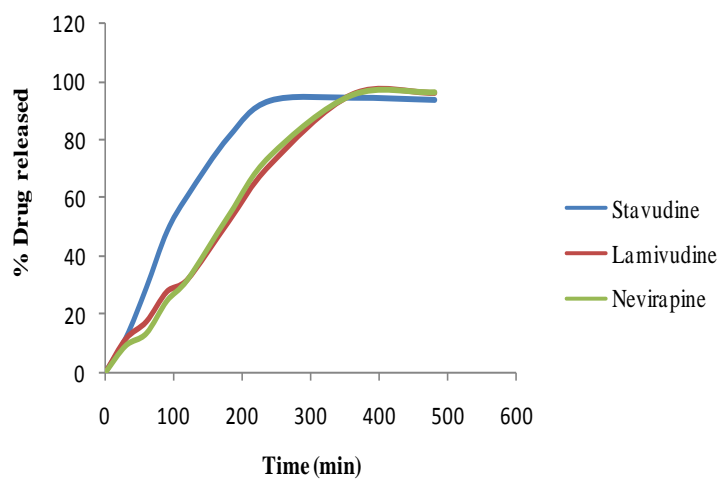

Fig. 2. Dissolution profile of W 59 suppository formulation.

\section{Results and Discussion}

Displacement value of the SLN drug mixture in Witepsol base was calculated and the average of five determinations was found to be $1.501 \pm 0.11$. Torpedo-shaped suppositories were produced. The color of the suppositories was white to off-white. surface abrasion was not observed during removal of the suppository from the mould and they were with good surface finish. Uniform distribution of SLN drug mixture and other additives was observed after slicing the suppositories lengthwise.

All batches of suppositories that were manufactured were assessed for weight uniformity and were found to comply with the requirements for weight uniformity of suppositories, as described in the British Pharmacopoeia (BP), which recommends a maximum percentage deviation of $5 \%$. There is slight lowering of the melting point range in formulations containing polysorbate 80 as surfactant. The melting range has a direct impact on the rate of drug release from suppository formulations, since the rate of drug release from fatty bases depends on the melting rate of the base. The content uniformity of all batches of suppositories in which content uniformity was investigated, was found to be within the limits prescribed in the first step of the official content uniformity specifications for suppositories listed in BP.

\subsection{In-vitro drug release studies}

In vitro drug release rates can be determined through dissolution testing and batch uniformity testing. These are valuable tools for the validation of dosage form performance. Like oral dosage forms, suppository dosage forms have not been investigated to great extent by establishing a correlation between the in vitro dissolution 
rate and in vivo absorption potential of compounds. In vitro dissolution testing for suppositories is not applicable for the assessment and confirmation of bioavailability following rectal administration. However, in vitro dissolution testing can be used during initial dosage form development and control of batch quality during production. In addition, dissolution testing can be used to provide valuable information regarding the physical stability of drugs in suppositories, in addition to the assessment of the reliability of dosage form performance.

Time needed for drug release from Witepsol base is too long. The amount of drug released from pure Witepsol base is very less. As stavudine and lamivudine are hydrophilic and nevirapine is a lipophilic drug, the release of nevirapine from fatty base was increased by addition of non-ionic surfactants. The effect of surfactants was shown to be concentration dependent. It has been observed that the use of surfactant in combination with fatty bases of high hydroxyl value improved the release of nevirapine from suppositories. The formulation prepared with polysorbate 80 at $0.5 \%$ concentration showed increased drug release from the base, than formulations prepared with $0.25 \%$ and $1 \%$ concentrations of polysorbate 80 . The formulations prepared with same concentration of polysorbate 20 and polysorbate 60 resulted in significant decrease in drug release. The rate of drug release from W37 formulation containing propylene glycol does not show much difference from the base formulation. Thickening agent colloidal silicon dioxide added at $0.5 \%$ concentration significantly improved the homogeneity and appearance of the suppositories (W48). The optimized formulation (W59) was selected for In vivo studies in juvenile rabbits.

\subsection{Stability studies}

The SLN suppositories stored at $4^{\circ} \mathrm{C}$ and room temperature for stability studies were evaluated for drug content and drug release. The rate of drug release was slightly reduced. Excessive softening is the major indication of instability in suppositories. On prolonged storage, semi synthetic fatty suppository bases were shown to subject to hardening, with a corresponding increase in melting times. The melting characteristics, hardness and drug release profiles were changed after storage for a few weeks. Hardening of suppositories in storage may be a consequence of polymorphic phase transitions, increased crystallinity and/or increased trans-esterification of the bases. Long term storage of suppositories manufactured using semisynthetic fatty suppository bases resulted in reduction in drug release from these dosage forms.

\section{Conclusion}

The combination of stavudine, lamivudine and nevirapine is FDA approved fixed dose combination for treatment of HIV/AIDS in adult and pediatric patients. Administration of stavudine, lamivudine and nevirapine in a suppository dosage form may be a useful alternative for the treatment of the HIV/AIDS, when patients especially children are 
unwilling or unable to take oral medications. Despite the apparent complexity of suppository formulations, these studies have shown the applicability of fatty bases with different physicochemical properties for the formulation SLN suppository dosage forms for pediatric use.

The formulations developed and assessed in these studies have defined a starting point for further studies in which the impact of the nature and physicochemical properties of each base in relation to the physicochemical properties of the drugs can be assessed. Further studies must be conducted on the basis of drug partitioning between suppository base and rectal fluid systems, to predict the process of drug release. The actual true validation of in vitro release testing of the suppository dosage forms remains in the evaluation of in vivo performance of these dosage forms. In vivo studies were conducted in juvenile and adult rabbits to determine the bioavailability of stavudine, lamivudine and nevirapine of the suppository dosage forms.

Pediatric FDCs represent a new era in the treatment of pediatric population with HIV. The development of pediatric fixed-dose combination formulations marks an important milestone for children living with HIV/AIDS, but more combination formulations must become available for pediatric use and at drastically reduced costs.

\section{References}

1. E. De Clercq, Biochim. Biophys. Acta 1587, 258 (2002). http://dx.doi.org/10.1016/S09254439(02)00089-3

2. J. W. Beach, Clin. Ther. 20, 2 (1998). http://dx.doi.org/10.1016/S0149-2918(98)80031-3

3. Guidelines for the Use of Antiretroviral Agents in HIV-Infected Adults and Adolescents (US Department of Health and Human Services, 2004).

4. J. E. Gallant, J. Clin. Virol. 25, 317 (2002). http://dx.doi.org/10.1016/S1386-6532(02)00024-0

5. S. F. Forsyth, P. D. French, E. Macfarlane, S. E. Gibbons, and R. F. Miller. Int. J. STD AIDS 16, 139 (2005). http://dx.doi.org/10.1258/0956462053057602

6. P. Lorenzi, V. M. Spicher, B. Laubereau, B. Hirschel, and C. Kind, AIDS 12, 2495 (1998). http://dx.doi.org/10.1097/00002030-199818000-00002

7. V. D. Linden, S. Callens, B. Brichard, and R. Colebunders, Expert Opin Pharmacother. 10(11), 1783 (2009). http://dx.doi.org/10.1517/14656560903012377

8. G. A. DeBoer, F. Moolenaar, L. G. J. Deleede, and D. D. Breimer. Clin. Pharmacokinetics 7, 285 (1982). http://dx.doi.org/10.2165/00003088-198207040-00002

9. $\quad$ L. R. Zawar, and G. S. Bhandari, J. Appl. Pharm. Sci. 02(07), 186 (2012). http://dx.doi.org/10.7324/JAPS.2012.2729

10. M. A El-Majri and R. K. Sharma, Int. J. Drug Delv. 2, 108 (2010). http://dx.doi.org/10.5138/ijdd.v2i2.31

11. E. Moghimipour, M. A. Dabbagh, and F. Zarif, Asian J. Pharm. Clin. Res. 3, 92 (2009).

12. M. L. Sah and T. R. Saini, Ind. J. Pharm. Sci. 70 (4), 498 (2008). http://dx.doi.org/10.4103/0250-474X.44602

13. F. A Oladimeji, S. I. Omoruyi, and C. O Onyeji, African J. Biotechnol. 5(19), 1775 (200

14. E. I. Taha, A.-A. A. Zaghloul, A. A. Kassem, and M. A. khan. Pharm. Dev. Tchnol. 8(1), 21 (2003).

15. S. Janicki, M. Sznitowska, W. Zebrowska, H. Gabiga, and M. Kupiec, Eur. J. Pharm. Biopharm. 52, 249 (2001). http://dx.doi.org/10.1016/S0939-6411(01)00187-4

16. M. G. Ahmed, V. G. Khakasa, N. Udupa, and K. Paranjyothy, Ind. J. Pharm. Sci. 63(3), 196 (2000). 
17. S. A. Ibrahim, T. H. El-Faham, S. S. Tous, and E. M. Mostafa, Int. J. Pharm. 61(1-2), 1 (1990). http://dx.doi.org/10.1016/0378-5173(90)90037-5

18. E. O. Akala, A. Adedoyin, and F. A. Ogunbona. Drug Dev. Indust. Pharm. 17(2), 303 (1991). http://dx.doi.org/10.3109/03639049109043827

19. E. Novak, D. W. Osborne, L. E. Matheson, E. L. Parrott, J. L. Lach, and W. B. Morrison, Drug Dev. Ind. Pharm. 17(3), 373 (1991).

20. L. Lachman, H. Lieberman, and J. L. Kanig, The Theory and Practice of Industrial Pharmacy, 12th Edition (Pitman Publishing, 1975) pp. 564-588.

21. E. O Akala, A. Adedoyin, and F. A. Ogunbona, Drug Dev. Ind. Pharm. 17(2), 303 (1991).

22. A. Babar, T. Bellete, and F. M. Plakogiannis, Drug Dev. Ind. Pharm. 25(2), 241 (1999). http://dx.doi.org/10.1081/DDC-100102166

23. N. J. Vidras, V. E. Reid, N. R. Bolidar, and F. M. Plakogiannis, J. Pharm. Sci. 71, 945 (1982).

24. I. Setnikar, and S. Fantelli, J. Pharm. Sci. 51, 566 (1962). http://dx.doi.org/10.1002/jps.2600510616

25. H. Loth, and P. Bosche, Pharmazie 51(8), 571(1996).

26. L. V. Allen, Compounding Suppositories Part I, Secundum Artem, 3(3). http://www.perrigo.com/business/pdfs/Sec\%20Artem\%203.3.pdf 